\title{
Editorial
}

\section{Urban Air Pollution Exposure - Measurement, Modeling and Assessment}

\author{
Sharad Gokhale ${ }^{*} \S$
}

\author{
Indian Institute of Technology Guwahati, Department of Civil Engineering, Guwahati 781 039, India
}

Exposure to air pollution in city centers is of major concern because of its health-risks to urban dwellers, trafficcorridor users and even to in-transit commuters. The steady growth in traffic is the major source of toxic air pollutants in urban centers these days. Therefore, studying exposure to air pollutants in urban centers is of special interests to environmental health scientists. This special issue is aimed to bring together studies on current practices of measurement and quantification of exposure levels and assessment of the associated risks to humans. The receptor-oriented approach, in which exposure is assessed at the receptor, is of particular importance compare with the conventional source-oriented approach. The articles of this issue engulf the four important aspects of this important topic.

The first paper describes various statistical modeling techniques and estimates the distributed lag that links the mortality rates with the exposure to air pollution. It

*Address correspondence to this author at the Indian Institute of Technology Guwahati, Department of Civil Engineering, Guwahati 781 039, India; Tel. +91361258 2419; Fax. +91 361258 2440; E-mails: sharadbg@iitg.ernet.in, sharadgokhale@gmail.com

${ }^{\S}$ Guest Editor concludes that the distributed lag effect may be attributed to the likely health-risks caused by the exposure to air pollution. The second paper presents the results of the personal exposure to carbon monoxide and fine particulate matter near arterial roadways, particularly from the twowheelers. The authors conclude that the exposure level to different pollutants may be affected by the characteristics of the road configuration. Exposure of parking attendants to air pollution is another important issue, which is dealt in the third paper. It describes the spatial and temporal variations in their exposure to carbon monoxide and ultra-fine particles. Authors conclude that the exposure level varies with the attendant's location with respect to traffic activity. While the first three papers are focused on exposure when people use urban corridors, the fourth paper presents the results of exposure to air pollutant on in-transit commuters in different modes. The authors conclude that the exposure of motorcyclists is higher than other modes of transport.

Air quality deterioration in urban centers and its impacts upon exposure are a cause of concern today. I would like to acknowledge the authors, reviewers, and Bentham Science Publishers for encouraging this special issue on this burning topic.

(C) Sharad Gokhale; Licensee Bentham Open.

This is an open access article licensed under the terms of the Creative Commons Attribution Non-Commercial License (http: //creativecommons.org/licenses/by$\mathrm{nc} / 3.0 /$ ) which permits unrestricted, non-commercial use, distribution and reproduction in any medium, provided the work is properly cited. 